\title{
Intention to Use Smartphones among Peruvian University Students
}

\author{
https://doi.org/10.3991/ijim.v13i03.9356
}

\author{
Mercedes Rojas-Osorio, Aldo Alvarez-Risco $(\bowtie)$ \\ Universidad de San Martin de Porres, Lima, Perú \\ aalvarezr@usmp.pe
}

\begin{abstract}
This document is a report on the findings of a study aims to investigate human motivations affecting an adoption decision for smartphone among Peruvian university students. This research investigates smartphone users' perception using technology acceptance model (TAM). It is analyzed perceived ease of use, perceived usefulness and attitude toward to keep using a smartphone as determinants for behavioral intention to keep using a smartphone between Peruvian university students, evaluating them with reliability and validity and confirming the hypotheses elaborated for the study. Findings indicate that the behavioral intention to keep using a smartphone (BIU) was significantly influenced by perceived ease of use (PEOU), perceived usefulness (PU) and attitude toward to keep using a smartphone (AKUS) and also, PEOU influenced significantly to PU. This study not only provides valuable information about students' the intention to keep using a smartphone, but also enriches the current literature, focusing on Peru, which has a different commercial characteristics and cultural background as compared to North America, Europe and Asia. According to the current literature review, this is the first study on this subject that specifically focuses on the use of smartphones by Peruvian university students.
\end{abstract}

Keywords - Intention to use, Peruvian students, Technology Acceptance Model, TAM, Smartphone

\section{Introduction}

The way in which people is in contact with other have been changing due to different tools and smartphones have an important place in this changing process because increased the Internet traffic for finding information, enjoy music and videos, and even manage the personal agenda for job and studies. Additionally, with the arrival of more sophisticated equipment, new operating systems, very useful applications to use them daily and even with the reduction of costs due to the arrival of new competitors has generated an increase in users. Some previous research focused in the evaluation of the implementation of mobile apps in daily learning activities [1], observation of implementing a mobile application news tool for disseminating messages in a university [2] and observation of the relationship between mobile phone usage in classroom in a university [3]. 
Specifically, Poushter [4] reported that in 2016 the percentage of smartphones penetration was being leaded by South Korea (88\%), Australia (77\%), and United States ( $72 \%)$. Peru reported only $25 \%$ ( $29 \%$ men, $21 \%$ women), $41 \%$ in people between 18 and 34 years old and $15 \%$ in older than 35 years old. Other report made it by Newzoo [5] show the list of countries by smartphone penetration in April 2017 is leaded by United Arab Emirates (80.6\%), Sweden (72.2\%), Switzerland (71.7\%), South Korea $(71.5 \%)$ and Taiwan (70.4\%). Peru is in 37 ranks with (36.0\%). The statistics show a unique growth, which is getting faster and for that reason is attractive for research activities as smartphones bring many functions that make life easier for people, through the rapid management of their information and many forms of communication. Despite what may have been investigated, it should be considered that smart phones are a new technology therefore there is a need to investigate its components linked to interpersonal and mass communication. This knowledge is expected to collaborate with the construction of theory for current communication technologies. To achieve this, it is necessary to evaluate both the factors that affect the use of smartphones by users, taking into account that there is little evidence of the profile. Specifically in the case of Peruvian university students, there is no previous evidence.

The main objective of the present investigation is to analyze the psychological factors of the users that generate an influence in the use of the smart phones. To this goal, the study use the framework of the technology acceptance model (TAM) developed by Davis, Bagozzi \& Warshaw [6] so the present study measure the influence of the perception of ease of use the smartphone (PEOU), perceived usefulness (PU) and, attitude toward to keep using the smartphone (AKUS) over the intention to keep using smartphones (IKU). It is valuable to evaluate the use of smartphones in the population of university students because according to the age they usually have a high usage is expected but is also evaluating how much of that use is related to their academic activities and is measured further how important it is for them to use the smartphone to solve their day to day life in college; there have no studies on this topic specifically in Peru, which has a low level of smartphone penetration (in comparison to other countries even in South America) and also have different habits as compared to other regions. In this situation, the current exploratory study focuses on Peruvian university students' smartphone preferences and practices. The literature review reveals that very few studies investigated the smartphone adoption and fewer studies have empirically tested university student's perceptions to explain the adoption of smartphone for their daily academic activities.

We aimed to supply answers these questions in this research:

1. What is the most frequently used app for Peruvian university students when performing their usual academic activities, and are female and male differences in relation to their preferences?

2. For how many years have, you used a smartphone and which operator currently provides you with the mobile phone service Between Peruvian university students?

3. What is the influence of perceived of ease of use the smartphone (PEOU) over perceived usefulness (PU)? 
4. What is the influence of perceived of ease of use the smartphone (PEOU) attitude toward to keep using smartphone (AKUS)?

5. What is the influence of perceived usefulness (PU) over attitude toward to keep using smartphone (A)?

6. What is the influence of attitude toward to keep using the smartphone (AKUS) over behavioral intention to use smartphone (IKU)?

7. What is the influence of perceived usefulness (PU) over behavioral intention to use smartphone (IKU)?

\section{$1.1 \quad$ Theoretical background}

Between the models most successfully employed in many field researches, the technological acceptance model (TAM) stands out. Davis, Bagozzi \& Warshaw [6] developed this model based on the theory of reason action (TRA) by Ajzen and Fishbein [7]. One important issue is that the TAM was especially developed to predict the acceptance of information systems by users in organizations, it means in a work facilities. According the authors of the model, the main aim of TAM is to explain the factors that determine the utilization of ICT by a number of users of technology. The TAM suggests that perceived usefullness and ease of use are determinants in an individual's intention to use a system. The TAM helps to know if a technology is going to be used in an optimal way but it is necessary to identify external variables that influence the usefulness and ease of use perceived by ICT users. Nowadays, the different organizations need their employees must use optimally the ICT. Also, universities are implementing more technology for supply education in undergraduate and postgraduate students and in this case these students face the same situation against ICT. The model seeks to predict the relative importance of perceived usefulness (PU) and perceived ease of use (PEOU), together with other variables relevant to specific research contexts, on either intention to use or actual use [6]. TAM is based on two main characteristics:

1. Perceived usefulness (PU). It refers to the degree to which a person believes that using a specific system will improve their performance on the usual activities (job for workers, classes for students).

2. Perceived ease of use (PEOU). It refers to the degree to which a person believes that using a particular system will make less effort to perform their usual tasks (job for workers, classes for students). The most important prediction during the use of the TAM is that PEOU affects PU, and both PEOU and PU jointly influence behavioral intention to use or intention to keep using a specific technology system. Also, the TAM suggests that it is necessary to add more relevant variables that may influence the two key variables of the model (PU and PEOU). When the model would be completed it will be more simple and general and finally useful to understand the relation and can improve behavior in any specific population. Research model is described in figure 1. 


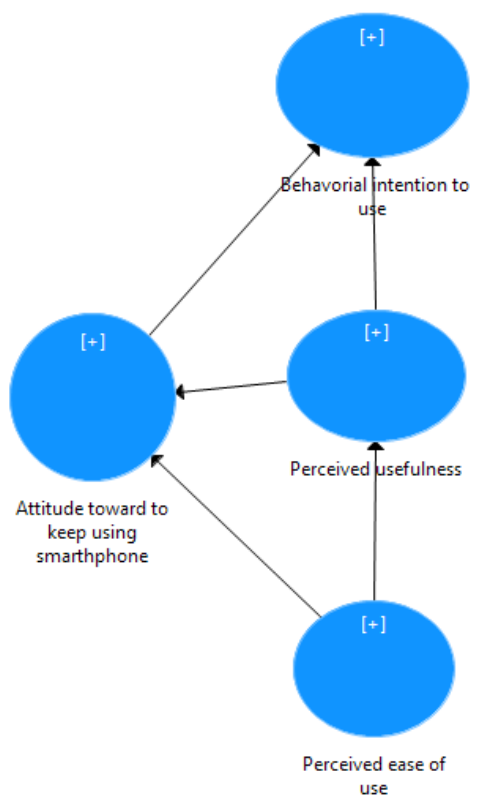

Fig. 1. Research model

\section{$2 \quad$ Literature Review}

In the literature, TAM has been studied for over 20 years. Reviewing the current literature, existing studies in the field can be grouped into some categories according to the kind of technology analyzed in the study. TAM has been tested as a theoretical framework showing its robustness in specific areas. First, in health area, some studies focused in acceptance of telemedicine like Hu study [8], which evaluated acceptance of telemedicine by physician in a tertiary hospital in Hong Kong. The perceived usefulness was found to be a significant determinant of attitude and intention but perceived ease of use was not. Holden \& Karsh [9] analyzed 20 studies developed in clinicians using health IT for patient care. Outcomes show that TAM predicts a substantial part of the use or acceptance of health IT. Secondly, in commercial services, Ha \& Stoel [10], analyzed acceptance of e-shopping and using a structural equation model revealed that consumer perceptions of usefulness and attitude toward e-shopping influence intention to shop online, while perceived ease of use does not influence attitude toward e-shopping. Aboelmaged \& Gebba [11] tested the model in acceptance of mobile banking services and the outcomes indicated a significant positive impact of attitude toward mobile banking and subjective norm on mobile banking adoption, and effects of behavioral control and usefulness on mobile banking adoption were insignificant. Also, Diatmika, Irianto \& Baridwan [12] focused on acceptance of accounting information system; they found that perceived usefulness, subjective norm, task technology fit and selfefficacy showed influence on behavior intention. Perceived ease of use, perceived behavior control and personal innovativeness in IT has no effect on behavior intention. 
Thirdly, in mobile use and services, Joo \& Sang [13] evaluated acceptance of use of smartphone in Korean consumers, using a structural equation model and demonstrated that Koreans' smartphone use is influenced more by motivations based on instrumental and goal-oriented use than by ritualized and less-goal oriented use. Park \& Kim [14] tested acceptance of mobile cloud services using a structural equation modeling analysis and found that user acceptance of mobile cloud services is largely affected by perceived mobility, connectedness, security, quality of service system, and satisfaction. About previous studies, literature show studies were developed in different regions:

- North America. United States: Landry, Griffeth \& Hartman [15]. Canada: Ifnedo [16].

- Asia. South Korea: Park [17]. Hong Kong: Cheung \& Vogel [18]. Jordan (Al-Adwan, Al-Adwan \& Smedley [19]. Saudi Arabia: Alharbi \& Drew [20]. Indonesia: Beldad \& Kusumadewi [21]. Thailand: Teo [22]. Kuwait: Al-Daihani [23].

- Europe. Italy: Persico, Manca \& Pozzi [24].

- Africa. South Africa: Chipps [25].

- Oceania. Australia: Atif, Richards, Busch \& Bilgin [26].

Previous studies show that the TAM is a well-suited model that allows explaining the adoption and use of different information and communication technology (ICT) systems. However, there is a gap of research for Latin American countries in this issue which is the focus of the current study: Peruvian students. In spite of low level of smartphone penetration in Peru, 64.1\% of population in Lima city, capital of Peru, has access to Internet and only $11.9 \%$ in rural areas accord INEI [27]. Having a smartphone gives many opportunities for the search of information but at the same time is a source of distraction for students, including during the dictation of classes by the teacher in the classroom. So are smartphones really being used correctly? Is it a misperception that the students waste time when they use the smart phone for a long time?

\section{$3 \quad$ Methodology}

For current study were employed both open-ended and closed-ended. Students from the business school of one private university in Lima, Peru were sampled. Data was collected between 25 August 2017 and 12 September 2017. A total of 404 students participated and completed the survey. Only 366 students completed the survey properly. In the research design, university students' sex, age, e-mail preference, app preference, smartphone usage time, amount of smartphone in the past, mobile phone company. In this context, students were asked:

1. What e-mail do you use most when doing your university tasks?

2. What is the most frequently used app when doing your college homework?

3 . What cycle are you currently in?

4. For how many years have, you used Smartphone.

5. How many Smartphones have you had before the current one?

6 . What operator currently provides you with the mobile phone service? 
Obtained data was evaluated by frequency ratios in developing a general understanding about commonly preferred digital sources of Peruvian university students. Next, it was explored what were perceived usefulness, perceived ease of use, attitude and behavioral intention in Peruvian university students. It was used as reference the instrument of Park and Chen [28]. Seventeen statements with each constructed described before in a Likert 5-points questionnaire were asked.

\section{- Perceived usefulness}

1. Using the smartphone in my job would enable me to accomplish tasks more quickly

2. Using the smartphone would improve my job performance

3. Using the smartphone would enhance my effectiveness on the job

4. Using the smartphone would make it easier to do my job

5. I would find the smartphone useful in my job

- Perceived ease of use

1. Learning to operate the smartphone would be easy for me

2. I would find it easy to get the smartphone to do what I want it to do

3. I would find the smartphone to be flexible to interact with

4. It would be easy for me to become skillful at using the smartphone

5. I would find the smartphone easy to use

- Behavioral intention

1. Whenever possible, I intend to use the smartphone in my job

2. To the extent possible, I would use the smartphone to do different things

3. I intend to increase my use of the smartphone in the future

- Attitude toward to keep using smartphone

1. Using the smartphone for my tasks is a good idea

2. Using the smartphone while do my tasks is terrific

3. Using the smartphone is beneficial to my tasks

4. I like using the smartphone for my tasks

\subsection{Validation with SEM-PLS}

Using Partial Least Squares Structural Equation Modeling (PLS-SEM) was analyzed the validity of construct and discriminant and, internal consistency by the composite reliability. SmartPLS statistical package accord Ringle, Wende \& Becker [29] is used to calculate the factorial structure of the indicators, using Partial Least Squares. SEM-PLS aims to predict the latent variables by estimating Partial Least Squares (PLS) and Principal Component Analysis (PCA). The main advantage of PLS is the greatest strength calculations to smaller samples and breach of statistical assumptions of the variables (non-normal distribution, different levels of measurement, multi collinearity, among others). With PLS structural equation modeling technique can be evaluated simultaneously two methods: the measurement model and the structural model. In the case of validity, the measurement model is used which involves the analysis of the reliability of each indicator, the internal consistency of each dimension, analysis of average variance extracted and discriminant validity. In a PLS model, the individual reliability of 
the indicators is assessed by examining the load between each indicator and dimension, accepting as reliable those above 0.706 loads, although some authors suggest not be so rigid in early stages of development instruments. Another measure used to evaluate the fit of the model is the average variance extracted that provides the amount of variance that a construct (dimension) obtains from its indicators about the error variance. A good fit requires values above $50 \%$.

\subsection{Validation of construct of behavioral intention to use with SEM-PLS}

Table 1 shows that all the factor weights of the dimensions of the behavioral intention to use are greater than the expected minimum (.706), with average variance extracted by scale between 67.1 and $76.6 \%$, and high levels of composite reliability (between .881 and .929). These values confirm the internal consistency and construct validity of each of the subscales of behavioral intention to use.

Table 1. Construct validity of the items of the scales of behavioral intention using Structural Equations of Variance using Partial Least Squares

\begin{tabular}{|c|c|c|c|c|}
\hline & Items & \begin{tabular}{c|} 
Load \\
ing
\end{tabular} & $\begin{array}{l}\text { Composite } \\
\text { reliability }\end{array}$ & $\begin{array}{l}\text { Extracted } \\
\text { variance }\end{array}$ \\
\hline \multirow{5}{*}{$\begin{array}{l}\text { Perceived } \\
\text { ease of use }\end{array}$} & Learning to operate the smartphone would be easy for me & .796 & .919 & 693 \\
\hline & $\begin{array}{l}\text { I would find it easy to get the smartphone to do what I want } \\
\text { it to do }\end{array}$ & .792 & & \\
\hline & I would find the smartphone to be flexible to interact with & .843 & & \\
\hline & $\begin{array}{l}\text { It would be easy for me to become skillful at using the } \\
\text { smartphone }\end{array}$ & .825 & & \\
\hline & I would find the smartphone easy to use & .902 & & \\
\hline \multirow{5}{*}{$\begin{array}{l}\text { Perceived } \\
\text { usefulness }\end{array}$} & $\begin{array}{l}\text { Using the smartphone in my job would enable me to accom- } \\
\text { plish tasks more quickly }\end{array}$ & .834 & .911 & .671 \\
\hline & Using the smartphone would improve my job performance & .762 & & \\
\hline & $\begin{array}{l}\text { Using the smartphone would enhance my effectiveness on } \\
\text { the job }\end{array}$ & .781 & & \\
\hline & Using the smartphone would make it easier to do my job & .857 & & \\
\hline & I would find the smartphone useful in my job & .859 & & \\
\hline \multirow{4}{*}{$\begin{array}{l}\text { Attitude to- } \\
\text { ward using } \\
\text { smartphone }\end{array}$} & Using the smartphone for my tasks is a good idea & .896 & .929 & .766 \\
\hline & Using the smartphone while do my tasks is terrific & .838 & & \\
\hline & Using the smartphone is beneficial to my tasks & .881 & & \\
\hline & I like using the smartphone for my tasks & .885 & & \\
\hline \multirow{3}{*}{$\begin{array}{l}\text { Behavioral } \\
\text { intention }\end{array}$} & Whenever possible, I intend to use the smartphone in my job & .852 & .881 & .712 \\
\hline & $\begin{array}{l}\text { To the extent possible, I would use the smartphone to do dif- } \\
\text { ferent things }\end{array}$ & .844 & & \\
\hline & I intend to increase my use of the smartphone in the future & .835 & & \\
\hline
\end{tabular}

*Source: 366 school business students. Self-prepared 


\section{$4 \quad$ Findings}

A total of 366 students completed the survey properly. Distribution of sample among two genders with 192 females (mean age $=21.53$; SD: 2.90) and 174 males (mean age =22.10; SD: 2.95) indicated no conspicuous biases. 117 students were between 2 to 5 academic cycles and 249 were between 6 to 10 academic cycles. About smartphone usage time, mean was 7.4 years (SD: 4.237) and about number of smartphones used in the past, mean was 3.64 (SD: 2.492).

Data of e-mail preference, app preference smartphone and Mobile Phone Company was evaluated. Gmail (51.9\%) and Hotmail (44.8\%) were the two emails preferred by the students for were the two emails preferred by the student's purposes. WhatsApp $(61.5 \%)$ and Facebook (37.4\%) were the two apps preferred by the students for were the two emails preferred by the student's purposes. Distribution of Mobile Phone Company were Claro (48.2\%), Movistar (25.7\%), Entel (22.2\%) and Bitel (3.9\%)

Also, figure 2 shows the research model tested.

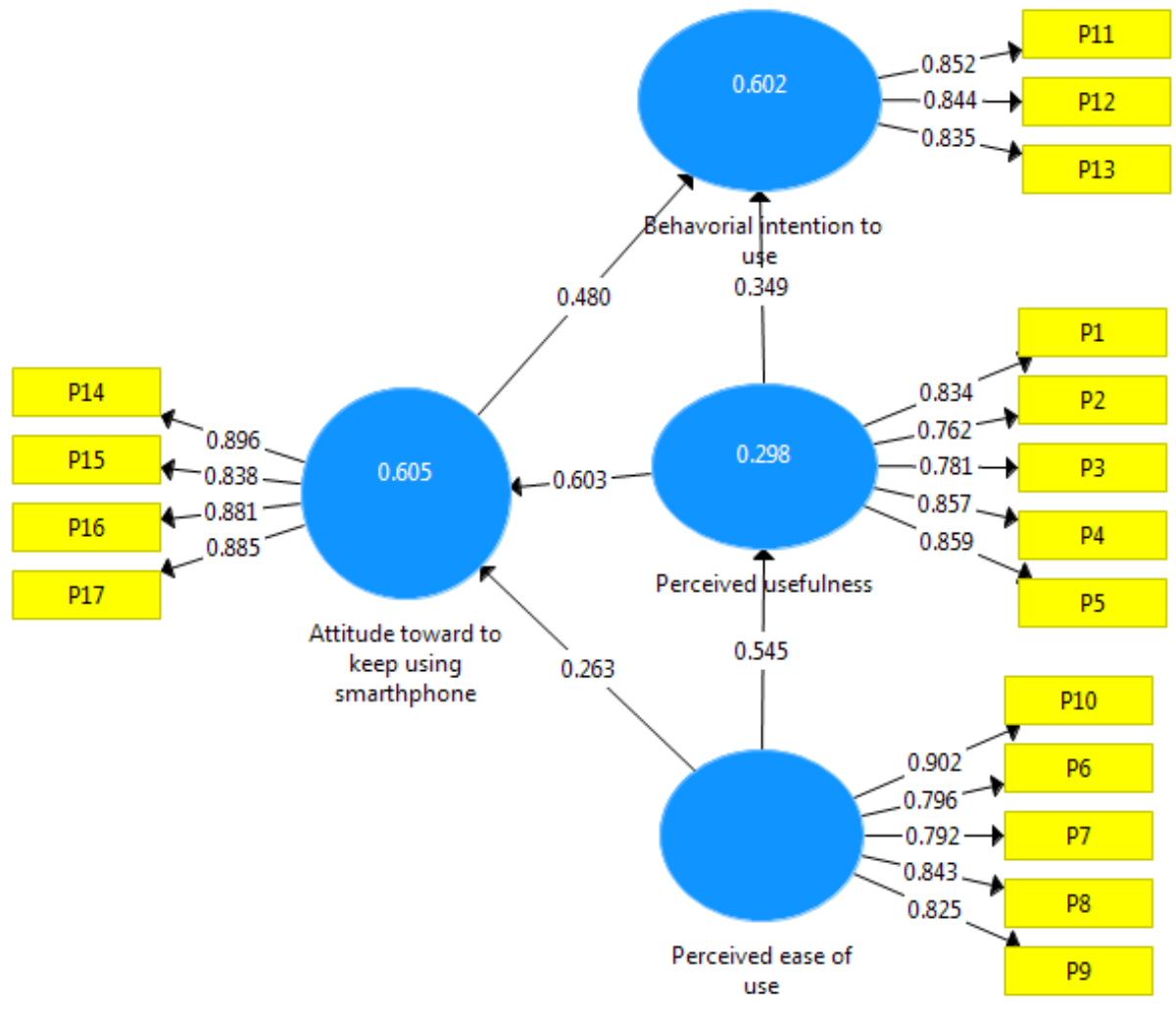

Fig. 2. Research model tested 
Considering the relation shown in fig. 2, we evaluated the objectives 3, 4, 5 and 6 :

- The influence of perceived of ease of use smartphone over perceived usefulness: The influence of perceived ease of use smartphone has a positive effect of 0.545 over perceived usefulness. The influence of perceived of ease of use smartphone explains $29.8 \%$ of the attitude toward to keep using smartphone.

- The influence of perceived of ease of use smartphone over attitude toward to keep using smartphone: The influence of perceived of ease of use smartphone has a positive effect of 0.263 over attitude toward to keep using smartphone.

- The influence of perceived usefullness over attitude toward to keep using smartphone: The influence of perceived usefulness has a positive effect of 0.603 over attitude toward to keep using smartphone. The influence of perceived usefulness together with perceived of use smartphone explains $60.5 \%$ of the attitude toward to keep using smartphone.

- The influence of attitude toward to keep using smartphone over intention to keep using smartphone: The influence of attitude toward to keep using smartphone has a positive effect of 0.480 over intention to keep using smartphone.

- The influence of perceived usefullness over intention to keep using smartphone: The influence of perceived usefullness has a positive effect of 0.349 over intention to keep using smartphone. The influence of perceived usefullness together with attitude toward to keep using smartphone explains $60.25 \%$ of the behavioral intention to use.

Table 2 shows significance of the path coefficients between the variables. It is included outcomes of bootstrapping with 5000 resample. It is verified that all values are significant.

Table 2. Significance of the path coefficients between the variables

\begin{tabular}{|l|c|c|c|c|}
\hline $\begin{array}{c}\text { Relations between variables } \\
\text { (Beta values) }\end{array}$ & Original sample & Sample mean & Standard error & T statistical \\
\hline AKUS $\rightarrow$ BIU & 0.480 & 0.480 & 0.118 & 4.049 \\
\hline PEOU $\rightarrow$ AKUS & 0.263 & 0.259 & 0.105 & 2.502 \\
\hline PEOU $\rightarrow$ PU & 0.545 & 0.542 & 0.100 & 5.443 \\
\hline PU $\rightarrow$ BIU & 0.349 & 0.350 & 0.119 & 2.934 \\
\hline PU $\rightarrow$ AKUS & 0.603 & 0.606 & 0.085 & 7.061 \\
\hline
\end{tabular}

*Source: Simulation through Bootstrapping. Resample (5000 times), $\mathrm{p}<0.01$

*Note: Attitude toward to keeping using smartphone (AKUS), Perceived usefulness (PU), Perceived ease of use (PEOU), Behavioral intention to use (BIU).

\section{Discussion}

The current study aims to investigate human motivations affecting an adoption decision for smartphone among Peruvian university students. Taking a different cultural background, when compared to North America, Europe and Asia, outcomes are noteworthy in order of enriching existing literature in the field. The outcomes strongly 
support the influences of variables to explain the behavioral intention to keep using smartphone.

About smartphone usage time the mean was 7.30 and looking mean age of sample, many have been initiating the use of smartphone since 15 years old; this information together with amount of smartphone in the past (3.64) shows that in approximately seven years, since 15 years old, students changed 3-4 times their smartphone, it means change device each two years. Other interesting information is about email preference because according to report of September 2017 of Email Client Market Share [30] the percentage of users using Gmail was about three times more than those using Hotmail but in current study the percentage is very similar. About usage of app, according to comscore.com, users using WhatsApp was about three times more than those using Facebook but in current outcomes, it was only double. Also, it is surprising that the former monopoly supplier in Peru for more than 20 years, Movistar, has only $25.7 \%$. This figure is almost half of the market leader, Claro, in this student sector with a value of $48.2 \%$.

The findings indicated that Behavior Intention of Use (BIU) was widely influenced by Perceived Usefulness (PU) and Attitude toward to Keep Using Smartphone (AKUS). Also, PEOU and PU had a positive influence to AKUS. During the study it was found that the impact of PU on AKUS was stronger than that of PEOU. These outcomes are consistent with previous studies as Rauniar, Rawski, Yang, and Johnson [31] in which PU influence positively over AKUS in 0.69 and PEOU influence positively in AKUS in 0.60. This outcome implies that Peruvian student's feelings about smartphone usefulness will play a more important factor that student's perception of easiness in determining physician's attitude toward to keep using smartphone. Also, PU was positively affected by PEOU. The relationship between PU and PEOU has been documented and the results confirmed the importance of the link between them as Wallace and Sheetz [32] for evaluate the adoption of software measures, Cheung \& Vogel [18] for acceptance of e learning, Joo \& Sang [10] for smartphone usage and Ooi \& Tan [33] for acceptance of smartphone credit card.

\section{Conclusion and Future Work}

This effort of adapting TAM into the investigation of business student's intention of smartphone use was successfully demonstrated in this research. One important component was the AKUS in predicting BIU in business students confirms the validity of TAM model as other previous reported like Kin \& Shin [34] for acceptance of smart watches and Ma, Chan \& Chen [35] for acceptance of smartphone in older adults. Developing studies that allow evaluating the acceptance of technology is a crucial aspect, for which the type of product or consumption that is thought to use must be taken into account. Certainly it is not the same to accept the use of a basic type of smartphone, perhaps more similar to the old phones than to accept a smartphone of last generation and likewise, it is not similar the acceptance of the use of smartphone depending on the type of contract of navigation; thus, while those who have unlimited services will be able to rely heavily on the use of the smartphone, those who have a prepaid service will 
have a restricted use in the university, being more similar to returning home and using the Internet via Wi-Fi as part of the Internet system at home.

The previous mentioned aspects are characteristics that must be taken into account for future studies so that the sample can be characterized, which has inside the conditioning factors for the results to be different. An additional aspect knows who pays for the mobile phone service because it will be different when the student pays directly with the money of his parents or his work and another one when his parents pay. It is also recommended to take into account these differential aspects for future studies. We should also mention that this is an initial study using a convenience sample. Future studies can also to use a high number of sample and more qualitative information after the main study. Also, cross-cultural studies can reveal deeper information for future studies. The use of TAM approach allows an easy and reliable methodology to measure acceptance to technology.

\section{$7 \quad$ References}

[1] Damyanov, I., \& Tsankov, N. (2018). Mobile Apps in Daily Learning Activities. International Journal of Interactive Mobile Technologies (iJIM), 12(6), 133-140 https://doi.org/10 .3991/ijim.v12i6.9659

[2] ALFarsi, G. M., Jabbar, J., \& ALSinani, M. (2018). Implementing a Mobile Application News Tool for Disseminating Messages and Events of AlBuraimi University College. International Journal of Interactive Mobile Technologies (iJIM), 12(7), 129-138 https://doi.org/10.3991/ijim.v12i7.9484

[3] Yunita, A., Nursechafia, N., Setiawan, E., Nugroho, H., \& Ramadhan, H. (2018). The Relationship between Mobile Phone Usage in Classroom and Academic Achievement in College Life. International Journal of Interactive Mobile Technologies (iJIM), 12(8), 96-103 https://doi.org/10.3991/ijim.v12i8.9530

[4] Poushter, J. (2016). Smartphone Ownership and Internet Usage Continues to Climb in Emerging Economies. Pew Research Center. Available at http://www.pewglobal.org/files/2016/02/pew_research_center_global_technology_report_final_february_22_2016.pdf

[5] Newzoo (2017). Top 50 countries by smartphone users and penetration. Available at https://newzoo.com/insights/rankings/top-50-countries-by-smartphone-penetration-and-users/ https://doi.org/10.1109/ICIMTech.2017.8273529

[6] Davis, F. D., Bagozzi, R. P., \& Warshaw, P. R. (1989). User acceptance of computer technology: a comparison of two theoretical models. Management science, 35(8), 982-1003 https://doi.org/10.1287/mnsc.35.8.982

[7] Ajzen, I. \& Fishbein, M. (1980). Understanding Attitudes and Predicting Social Behaviour. Prentice-Hall, Englewood Cliffs https://doi.org/10.12962/j24068535.v15i2.a663

[8] Hu, P. J., Chau, P. Y., Sheng, O. R. L., \& Tam, K. Y. (1999). Examining the technology acceptance model using physician acceptance of telemedicine technology. Journal of management information systems, 16(2), 91-112 https://doi.org/10.108 0/07421222.1999.11518247

[9] Holden, R. J., \& Karsh, B. T. (2010). The technology acceptance model: its past and its future in health care. Journal of biomedical informatics, 43(1), 159-172 https://doi.org/10.1 $\underline{016 / j . j b i .2009 .07 .002}$ 
[10] Ha, S., \& Stoel, L. (2009). Consumer e-shopping acceptance: Antecedents in a technology acceptance model. Journal of Business Research, 62(5), 565-571 https://doi.org/10 $.1016 /$ j.jbusres.2008.06.016

[11] Aboelmaged, M. \& Gebba, T. R. (2013). Mobile banking adoption: an examination of technology acceptance model and theory of planned behavior. International Journal of Business Research and Development, 2(1) https://doi.org/10.24102/ijbrd.v2i1.263

[12] Diatmika, I. W. B., Irianto, G., \& Baridwan, Z. (2016). Determinants of behavior intention of accounting information systems based information technology acceptance. Imperial Journal of Interdisciplinary Research, 2(8)

[13] Joo, J., \& Sang, Y. (2013). Exploring Koreans' smartphone usage: An integrated model of the technology acceptance model and uses and gratifications theory. Computers in Human Behavior, 29(6), 2512-2518 https://doi.org/10.30651/must.v2i2.883

[14] Park, E., \& Kim, K. J. (2014). An integrated adoption model of mobile cloud services: exploration of key determinants and extension of technology acceptance model. Telematics and Informatics, 31(3), 376-385 https://doi.org/10.1109/EDUCON.2017.7942861

[15] Landry, B. J., Griffeth, R., \& Hartman, S. (2006). Measuring student perceptions of blackboard using the technology acceptance model. Decision Sciences Journal of Innovative Education, 4(1), 87-99 https://doi.org/10.1111/i.1540-4609.2006.00103.x

[16] Ifinedo, P. (2017). Examining students' intention to continue using blogs for learning: Perspectives from technology acceptance, motivational, and social-cognitive frameworks. Computers in Human Behavior, 72, 189-199 https://doi.org/10. 1016/j.chb.2016.12.049

[17] Park, S. Y. (2009). An analysis of the technology acceptance model in understanding university students' behavioral intention to use e learning. Journal of Educational Technology \& Society, 12(3), 150

[18] Cheung, R., \& Vogel, D. (2013). Predicting user acceptance of collaborative technologies: An extension of the technology acceptance model for e learning. Computers \& Education, 63, 160-175 https://doi.org/10.1016/i.compedu.2012.12.003

[19] Al-Adwan, A., Al-Adwan, A., \& Smedley, J. (2013). Exploring student's acceptance of elearning using Technology Acceptance Model in Jordanian universities. International Journal of Education and Development using Information and Communication Technology, $9(2), 4$

[20] Alharbi, S., \& Drew, S. (2014). Using the technology acceptance model in understanding academics' behavioural intention to use learning management systems. International Journal of Advanced Computer Science and Applications, 5(1), 143-155 https://doi.org/10.1 4569/IJACSA.2014.050120

[21] Beldad, A., \& Kusumadewi, M. C. (2015). Here is my location, for your information: The impact of trust, benefits, and social influence on location sharing application use among Indonesian university students. Computers in human behavior, 49, 102-110 https://doi.org/10.1016/j.chb.2015.02.047

[22] Teo, T. (2016). Modelling Facebook usage among university students in Thailand: the role of emotional attachment in an extended technology acceptance model. Interactive Learning Environments, 24(4), 745-757 https://doi.org/10.1080/10494820.2014.917110

[23] Al-Daihani, S. M. (2016). Students' adoption of Twitter as an information source. An exploratory study using the Technology Acceptance Model. Malaysian Journal of Library and Information Science, 21(3), 57-69 https://doi.org/10.22452/mjlis.vol21no3.4

[24] Persico, D., Manca, S., \& Pozzi, F. (2014). Adapting the Technology Acceptance Model to evaluate the innovative potential of e-learning systems. Computers in Human Behavior, 30, 614-622 https://doi.org/10.1016/j.chb.2013.07.045

[25] Chipps, J., Kerr, J., Brysiewicz, P., \& Walters, F. (2015). A survey of University students' perceptions of learning management systems in a low-resource setting using a technology acceptance model. CIN: Computers, Informatics, Nursing, 33(2), 71-77 
[26] Atif, A., Richards, D., Busch, P., \& Bilgin, A. (2015). Assuring graduate competency: a technology acceptance model for course guide tools. Journal of Computing in Higher Education, 27(2), 94-113 https://doi.org/10.1007/s12528-015-9095-4

[27] INEI (2013). Estadísticas de las tecnologías de información y comunicación en los Hogares. Available at https://www.inei.gob.pe/media/MenuRecursivo/boletines/tecnologias-de-informacion-y-comunicacion-en-los-hogares-oct-dic-2013.pdf

[28] Park, Y., \& Chen, J. V. (2007). Acceptance and adoption of the innovative use of smartphone. Industrial Management \& Data Systems, 107(9), 1349-1365 https://doi.org/10.1108/02635570710834009

[29] Ringle, C. M., Wende, S., \& Becker, J. M. (2015). SmartPLS 3. Boenningstedt: SmartPLS $\mathrm{GmbH}$, http://www.smartpls.com

[30] Email Client Market Share (2017). Report September 2018. Available at https://emailclientmarketshare.com

[31] Rauniar, R., Rawski, G., Yang, J., \& Johnson, B. (2014). Technology acceptance model (TAM) and social media usage: an empirical study on Facebook. Journal of Enterprise Information Management, 27(1), 6-30 https://doi.org/10.1108/JEIM-04-2012-0011

[32] Wallace, L. G., \& Sheetz, S. D. (2014). The adoption of software measures: A technology acceptance model (TAM) perspective", Information \& Management, 51(2), 249-259 https://doi.org/10.1016/j.im.2013.12.003

[33] Ooi, K. B., \& Tan, G. W. H. (2016). Mobile technology acceptance model: An investigation using mobile users to explore smartphone credit card. Expert Systems with Applications, 59, 33-46 https://doi.org/10.1016/j.eswa.2016.04.015

[34] Kim, K. J., \& Shin, D. H. (2015). An acceptance model for smart watches: implications for the adoption of future wearable technology. Internet Research, 25(4), 527-541 https://doi.org/10.1108/IntR-05-2014-0126

[35] Ma, Q., Chan, A. H., \& Chen, K. (2016). Personal and other factors affecting acceptance of smartphone technology by older Chinese adults. Applied ergonomics, 54, 62-71 https://doi.org/10.1016/j.apergo.2015.11.015

\section{Authors}

Mercedes Rojas-Osorio is a Peruvian Educator specialized in Information and communications technology. Also Master in Business and Administration, by a European University, in Creation and Management of Companies. She has more than 10 of experience in development of projects and education programs using online and hydrid types of classes. Currently, she is candidate to Doctor in Education Technology by the Universidad de Murcia (Spain).

Aldo Alvarez-Risco is a Peruvian Educator, specialized in Sustainability and Health Services. He is pharmacist, Master in Pharmacology and Doctor in Pharmacy and Biochemistry by Universidad Nacional Mayor de San Marcos (Perú). Also, he is current candidate of $\mathrm{PhD}$ by Universidad Autónoma de Nuevo León (México). He has experience as researcher and lecturer in undergraduate and postgraduate programs since 2002 and he was speaker in academic events in 22 countries.

Article submitted 2018-08-06. Resubmitted 2019-01-06. Final acceptance 2019-01-30. Final version published as submitted by the authors. 